\title{
SKLB060 Reversibly Binds to Colchicine Site of Tubulin and Possesses Efficacy in Multidrug-Resistant Cell Lines
}

\author{
Wei Yan ${ }^{\mathrm{a}}$ Tao Yang ${ }^{\mathrm{a}}$ Jianhong Yang ${ }^{\mathrm{a}}$ Taijin Wang ${ }^{\mathrm{a}}$ Yamei Yu ${ }^{\mathrm{a}}$ Yuxi Wang ${ }^{\mathrm{a}}$ \\ Qiang Chen ${ }^{a}$ Peng Baia Dan Lia Haoyu Ye ${ }^{a}$ Qiang Qiu ${ }^{a}$ Yongzhao Zhou ${ }^{b}$ \\ Yiguo $\mathrm{Hu}^{\mathrm{a}}$ Shengyong Yang ${ }^{\mathrm{a}}$ Yuquan Wei ${ }^{\mathrm{a}}$ Weimin $\mathrm{Li}^{\mathrm{b}}$ Lijuan Chen ${ }^{\mathrm{a}, \mathrm{c}}$ \\ aState Key Laboratory of Biotherapy and Cancer Center, West China Hospital, Sichuan University, and \\ Collaborative Innovation Center for Biotherapy, Chengdu, bDepartment of Respiratory Medicine, West \\ China Hospital, Sichuan University, Chengdu, 'School of Pharmacy, Chengdu University of TCM, The \\ Ministry of Education Key Laboratory of Standardization of Chinese Herbal Medicine, State Key \\ Laboratory Breeding Base of Systematic Research, Development and Utilization of Chinese Medicine \\ Resources, Chengdu, China
}

\section{Key Words}

Tubulin • Cancer • Colchicine • Reversible • 4-substituted coumarins • SKLB060 • Multidrug Resistance

\begin{abstract}
Background/Aims: Many tubulin inhibitors are in clinical use as anti-cancer drugs. In our previous study, a novel series of 4-substituted coumarins derivatives were identified as novel tubulin inhibitors. Here, we report the anti-cancer activity and underlying mechanism of one of the 4-substituted coumarins derivatives (SKLB060). Methods: The anti-cancer activity of SKLB060 was tested on 13 different cancer cell lines and four xenograft cancer models. Immunofluorescence staining, cell cycle analysis, and tubulin polymerization assay were employed to study the inhibition of tubulin. $N, N^{\prime}$-Ethylenebis(iodoacetamide) assay was used to measure binding to the colchicine site. Wound-healing migration and tube formation assays were performed on human umbilical vascular endothelial cells to study antivascular activity (the ability to inhibit blood vessel growth). Mitotic block reversibility and structural biology assays were used to investigate the SKLB060-tubulin bound model. Results: SKLB060 inhibited tubulin polymerization and subsequently induced G2/M cell cycle arrest and apoptosis in cancer cells. SKLB060 bound to the colchicine site of $\beta$-tubulin and showed antivascular activity in vitro. Moreover, SKLB060 induced reversible cell cycle arrest and reversible inhibition of tubulin polymerization. A mitotic block reversibility assay showed that the effects of SKLB060 have greater reversibility than those of colcemid (a reversible tubulin inhibitor), indicating that SKLB060 binds to tubulin in a totally reversible manner. The crystal structures of SKLB060-tubulin complexes confirmed that SKLB060 binds to the colchicine site, and the natural coumarin ring in SKLB060 enables reversible binding. Conclusions: These
\end{abstract}

W. Yan, T. Yang and J. Yang contributed equally to this work.

and Weimin Li

KARGER
State Key Laboratory of Biotherapy and Cancer Center, West China Hospital, Sichuan

University and Collaborative Innovation Center for Biotherapy, Chengdu (China)

E-Mail chenlijuan125@163.com,weimi003@yahoo.com 
results reveal that SKLB060 is a powerful and reversible microtubule inhibitor that binds to the colchicine site and is effective in multidrug-resistant cell lines.

\section{Introduction}

Tubulin, an $\alpha \beta$-heterodimer, assembles into microtubules in a head-to-tail manner, and these can polymerize and depolymerize to regulate normal cell physiological activities [1]. Tubulin participates in numerous cellular processes, including the maintenance of cell shape and cell division. In mitosis, which is an important cellular event during cancer cell proliferation, tubulin is needed for the formation of spindles, and this makes it an attractive target in the design of anti-cancer drugs [2].

Many microtubule inhibitors (MTIs) targeting the taxane or vinca alkaloid binding sites such as taxanes, vinca alkaloids, and epothilones are used in the treatment of many solid and hematological malignancies [3-5]. Although MTIs have been demonstrated to exert a high level of anti-cancer activities during clinical treatment or preclinical testing, their effectiveness is limited by multidrug resistance (MDR)[6, 7]. To avoid MDR, researchers once focused on the development of irreversible tubulin inhibitors $[8,9]$, because resistant tumor cells cannot escape the effects of irreversibly bound compounds by reducing their affinity for the target or by enhancing drug efflux. However, these irreversible compounds that bind to tubulin usually result in severe toxicity, and thus their clinical use is limited [10].

Apart from the well-known taxane or vinca alkaloid binding sites, there are other binding sites on tubulin, such as the colchicine [11], laulimalide [12], maytansine [13] and pironetin [14] (binding to $\alpha$-tubulin) binding sites. Among them, the colchicine binding site may be a promising target because most tubulin inhibitors that bind to this site are not substrates of MDR proteins [15]. Some compounds, such as combretastatin [16] and MPC-6827[17], are in clinical trials as cancer treatments. However, no colchicine-binding agents have been approved for the treatment of cancer to date.

MPC-6827, also known as verubulin, is a powerful polymerization inhibitor with subto-low nmol/L growth inhibitory potencies against tumor cells. MPC-6827 competes with colchicine binding and disrupts the formation of microtubules in a variety of tumor cell lines at the micro-nanomolar level [17]. However, in 2011, Myrexis Inc. suspended clinical trials of MPC-6827 because of its toxic effects [18]. In our previous study, we designed a serious of 4-substituted coumarins as a novel class of potent tubulin inhibitors-based on the basic skeleton structure of MPC-6827-that were not substrates of MDR proteins [17, 19]. Here, we further report one of the 4-substituted coumarins, SKLB060, as a powerful and reversible microtubule inhibitor that binds to the colchicine site with efficacy in multidrugresistant tumor models. Notably, we found that SKLB060 and MPC-6827 exhibited similar in vitro and in vivo anti-cancer activities, but SKLB060 showed much lower toxicity than MPC6827. Using a mitotic block reversibility assay, we found that MPC-6827 binds irreversibly to tubulin, while SKLB060 is reversible. We hypothesized that the development of reversible microtubule-inhibitors that bind to the colchicine site might be a feasible approach to avoid drug resistance caused by MDR and reduce toxicity. The X-ray crystal structures of the MPC-6827-, SKLB060- and colchicine-tubulin complex were resolved to investigate the underlying mechanisms.

\section{Materials and Methods}

\section{Reagents}

$N, N^{\prime}$-Ethylenebis(iodoacetamide) (EBI), paclitaxel (PTX), colchicine, colcemid, MPC-6827, and Adriamycin (ADM) were purchased from Selleck Chemicals (Houston, TX, USA). Penicillin, streptomycin, 4, 6-diamidino-2-phenylindole (DAPI), MTT, dimethyl sulfoxide (DMSO), and propidium iodide (PI) were purchased from Sigma-Aldrich Shanghai Trading Co. Ltd. (Shanghai, China). Annexin V/PI Apoptosis 
Yan et al.: SKLB060 Reversibly Binds to Colchicine Site of Tubulin with Efficious Antitumor Activity

Detection Kit was obtained from Invitrogen (Carlsbad, CA, USA). Porcine brain tubulin was purchased from Cytoskeleton Inc. (Denver, CO, USA) and supplied at $10 \mathrm{mg} / \mathrm{mL}$ in general tubulin buffer (80 mM PIPES [pH 6.9]; $2 \mathrm{mM} \mathrm{MgCl}$; $0.5 \mathrm{mM}$ ethylene glycol tetraacetic acid [EGTA]; and $1 \mathrm{mM}$ guanosine tri-phosphate [GTP]) and preserved at $-80^{\circ} \mathrm{C}$ until use. The $\alpha$-tubulin antibody (SC-53646), $\beta$-tubulin antibody (SC-365791) and glyceraldehyde 3-phosphate dehydrogenase (GAPDH) antibody (SC-293335) were obtained from Santa Cruz Biotechnology Shanghai Trading Co. Ltd. (Shanghai, China). Anti-mouse second antibody (A0208) was from Beyotime Biotechnology (Shanghai, China). PIPES, EGTA, $\mathrm{MgCl}_{2}, \mathrm{NaCl}$, glycerol, and other conventional reagents were purchased from Kelun Pharmaceutical Co., Ltd. (Chengdu, China) or Sangon Biotech Co., Ltd. (Shanghai, China).

\section{Cell lines and cell culture}

Human ovarian carcinoma SKVO3 cells, human lung cancer cell lines H460, A549, and HCC827, human hepatoma HepG2 cells, human colon HCT-116 cancer cells, and human breast cancer MDA-MB-231 cells were obtained from the American Type Culture Collection (ATCC). Human ovarian carcinoma A2780 and A2780/T cells (resistant to PTX), human colon HCT-8 and HCT-8/V cancer cells (resistant to vinblastine), and human MCF-7 and MCF-7/ADR breast cancer cells (resistant to ADM) were obtained from the KeyGEN Biotech Co. (Nanjing, Jiangsu, China). Cells were cultured in RIPM 1640 or Dulbecco's modified Eagle medium (DMEM) containing 10\% fetal bovine serum (FBS), $100 \mathrm{U} / \mathrm{mL}$ penicillin, and $100 \mu \mathrm{g} / \mathrm{mL}$ streptomycin at $37^{\circ} \mathrm{C}$ in an atmosphere of $5 \% \mathrm{CO}_{2}$. All cells were tested and authenticated annually by an AmpFLSTR Identifiler PCR Amplification Kit (Applied Biosystems, Carlsbad, CA, USA) in our laboratory; the cells were last tested in October 2017.

\section{Cell proliferation assay}

The antiproliferative activities of these compounds were tested in SKVO3, A2780, A2780/T, H460, A549, HCC827, HepG2, HCT-116, HCT-8 and HCT-8/V, MDA-MB-231, MCF-7, and MCF-7/ADR cells. Cells in logarithmic phase were seeded in 96-well plates and allowed to adhere for $24 \mathrm{~h}$. Cells were then incubated with different concentrations of compounds for $72 \mathrm{~h}$. MTT was subsequently added for an extra 2-3 h incubation. The MTT formazan precipitate was dissolved in $150 \mu \mathrm{L}$ DMSO, and the absorbance was measured at a wave length of $570 \mathrm{~nm}$ by a SpectraMax M5 Microtiter Plate Luminometer (Molecular Devices, Sunnyvale, CA, USA).

\section{Immunofluorescence staining}

A2780 cells were seeded into 6-well plates and treated with different compounds as indicated for 16 h. Cells were fixed with $4 \%$ paraformaldehyde and then penetrated with phosphate-buffered saline (PBS) containing $0.5 \%$ Triton X-100. After blocking for $30 \mathrm{~min}$ in $5 \%$ goat serum albumin at room temperature, cells were incubated with a monoclonal antibody (anti- $\alpha$-tubulin, Santa Cruz Biotechnology) at $4^{\circ} \mathrm{C}$ for 12 h. Cells were washed 3 times by PBS after staining with the fluorescence antibody and DAPI labeling of the nuclei. Cells were again washed 3 times and visualized using a fluorescence microscope (Olympus, Tokyo, Japan).

\section{In vitro tubulin polymerization assay}

Tubulin (cytoskeleton, $3 \mathrm{mg} / \mathrm{mL}$ ) was resuspended in PEM buffer [80 mM PIPES, (pH 6.9), $0.5 \mathrm{mM}$ EGTA, $2 \mathrm{mM} \mathrm{MgCl}_{2}$ ] containing 15\% glycerol and pre-incubated with compounds or vehicle DMSO on ice. PEG containing GTP was added at the final concentration of $1 \mathrm{mM}$ before detection of the tubulin polymerization reaction. The reaction was monitored by a spectrophotometer in absorbance at $340 \mathrm{~nm}$ at $37^{\circ} \mathrm{C}$ every $2 \mathrm{~min}$. The final concentrations of the compounds were as follows: SKLB060 (1, 5, and $25 \mu \mathrm{M})$, MPC-6827 (1, 5 , and $25 \mu \mathrm{M})$.

\section{Cell cycle analysis}

A2780 and A2780/T cells were incubated with various concentrations of SKLB060 for $16 \mathrm{~h}$ at $37^{\circ} \mathrm{C}$. The cells were collected and washed by PBS and fixed in cold $70 \%$ ethanol overnight at $4^{\circ} \mathrm{C}$. Cells were washed again by PBS, and the cell DNA was stained with $50 \mu \mathrm{g} / \mathrm{mL}$ PI containing $1 \mathrm{mg} / \mathrm{mL}$ of DNase-free RNase A for a minimum of $10 \mathrm{~min}$. The samples were analyzed by a flow cytometer (BD FACSCalibur, BD Biosciences, Franklin Lakes, NJ, USA). 


\section{Cellular Physiology Cell Physiol Biochem 2018;47:489-504 \\ \begin{tabular}{l|l} 
and Biochemistry Published online: May 24, 2018 & $\begin{array}{l}\text { (c) } 2018 \text { The Author(s). Published by S. Karger AG, Basel } \\
\text { www.karger.com/cpb }\end{array}$
\end{tabular} \\ Yan et al.: SKLB060 Reversibly Binds to Colchicine Site of Tubulin with Efficious Antitumor}

Activity

Apoptosis analysis

A2780 and A2780/T cells were incubated with various concentrations of SKLB060 for $48 \mathrm{~h}$ at $37^{\circ} \mathrm{C}$. The cells were collected and washed by PBS and stained with annexin V and PI. Samples were analyzed by a flow cytometer (BD FACS Calibur).

\section{EBI competition assay}

A2780 cells were incubated with different compounds for $2 \mathrm{~h}$. EBI $(100 \mu \mathrm{M})$ was added to the cells and they were incubated for another $2 \mathrm{~h}$. Total proteins were lysed with radioimmunoprecipitation lysis buffer and subjected to western blot analysis for $\beta$-tubulin. The detailed methods of western blot are described in our previous study [19]. GAPDH was employed as the loading control.

\section{Wound healing assay}

Human umbilical vascular endothelial cells (HUVECs) were incubated in DMEM medium. Cells grew to confluence in 6-well plates and were incubated without FBS for $16 \mathrm{~h}$ to inactivate the cells. Monolayer cells were wounded by scratching with a pipet tip and washed with PBS. Fresh DMEM containing vehicle or different concentrations of SKLB060 was added to the scratched monolayers. After $24 \mathrm{~h}$, images were taken by fluorescence microscope. The cells were quantified by manual counting, and the percentage of migrated cells inhibited by compound SKLB060 was expressed in relation to those in the vehicle wells.

\section{Tube formation assay}

BD Matrigel matrix (BD Biosciences) was thawed at $4^{\circ} \mathrm{C}$ overnight, and HUVECs $\left(2-4 \times 10^{4}\right)$ suspended in DMEM were seeded in 96-well culture plates after polymerization of the Matrigel at $37^{\circ} \mathrm{C}$ for $30 \mathrm{~min}$. Cells were then treated with different concentrations of SKLB060 or vehicle. After 6-8 h, cells were photographed with a digital camera attached to an inverted microscope.

Animal tumor models and treatments

We established A2780, A2780/T, MCF-7, and MCF-7/ADR in vivo xenograft models with a established method [20]. Mice were randomly assigned to groups representing each tumor xenograft model. We used 5-6-week-old female Balb/C and athymic nude mice, and implanted the indicated number of cells suspended in 100 CE HBSS into the right flanks. When tumor volumes reached $100 \mathrm{~mm}^{3}$, the animals were treated with vehicle (2.5\% Tween-80 and 2.5\% ethanol), SKLB060, PTX, or ADM. Signs of toxicity and mortality rates were recorded daily. Tumor volumes and body weights were measured every 2 days by caliper (calculated volume $\left(\mathrm{mm}^{3}\right)=\pi / 6 \times$ length $\times$ width $\times$ width). The antitumor activity of the compounds was evaluated by tumor inhibitor $=(1-$ tumor weight of treated-group/tumor weight of control group $) \times 100 \%$. The animal studies were conducted in accordance with the Institutional Guide for the Care and Use of Laboratory Animals. All protocols involving mice were approved by the Animal Care and Use Committee of Sichuan University (Chengdu, Sichuan, China).

\section{Mitotic block reversibility assay}

A2780 cells were plated in 6-well plates and allowed to grow for $24 \mathrm{~h}$. Test compounds were added to the cells to give final concentrations of 1-3, $000 \mathrm{nmol} / \mathrm{L}$. After $12 \mathrm{~h}$ of incubation, cells were harvested and washed twice followed by re-suspension in $4 \mathrm{~mL}$ of the same media; 2-mL aliquots were immediately taken for cell cycle evaluation ( $\mathrm{T}=0 \mathrm{~h}$ ), with the remaining $2 \mathrm{~mL}$ returned to fresh flasks for 10 -h incubation periods in compound-free media. The remaining cells were used for cell cycle evaluation $(\mathrm{T}=10 \mathrm{~h})$. Reversible ratios were calculated by dividing the minimum drug concentration required to maintain complete mitotic block $(\mathrm{CMB})$ at $10 \mathrm{~h}$ by the minimum concentration required to initially induce $\mathrm{CMB}$ at $0 \mathrm{~h}$.

\section{Structural biology}

Porcine brain tubulin from Cytoskeleton Inc. was used for a structural biology study. The preparation of the crystals of the T2R-TTL complex (T2: $\alpha \beta$-tubulin heterodimer, R: the stathmin-like protein RB3, TTL: tubulin tyrosine ligase) is described in our previous study [14]. To soak the compounds into the crystals, $0.1 \mu \mathrm{L}$ of the compound solution (10 mM in DMSO) was added to the $2-\mu \mathrm{L}$ crystal-containing drops for $24 \mathrm{~h}$ at $20^{\circ} \mathrm{C}$. Beamlines BL17U1 and BL19U1 at the Shanghai Synchrotron Radiation Facility were used to obtain $\mathrm{X}$-ray diffraction data. Determination of the structure and the refinement protocols were the same as those in our previous study [14]. PYMOL and Discovery Studio 4.5 Client were used to generate the Fig., and the data and refinement statistics are given in Table 1. 
Yan et al.: SKLB060 Reversibly Binds to Colchicine Site of Tubulin with Efficious Antitumor Activity

\begin{tabular}{|c|c|c|c|c|c|}
\hline \multirow{16}{*}{$\begin{array}{l}\text { Table 1. Data } \\
\text { collection } \\
\text { refinement }\end{array}$} & & \multicolumn{4}{|c|}{ Ligand (PDB code) } \\
\hline & & Colchicine (5XIW) & MPC-6827 (5XKF) & SKLB060 (5XKG) & apo (5XP3) \\
\hline & Data collection statistics & & & & \\
\hline & Wavelength ( $\AA$ ) & 0.97845 & 0.97845 & 0.97845 & 0.97845 \\
\hline & Resolution range $(\AA)$ & $50.0-2.95(3.04-2.95)$ & $50.0-2.80(2.88-2.80)$ & $50.0-2.15(2.27-2.20)$ & $50.0-2.30(2.37-2.30)$ \\
\hline & Space group & P $22_{1} 2_{1} 2_{1}$ & $\mathrm{P} 22_{1} 2_{1} 2_{1}$ & P $2_{1} 2_{1} 2_{1}$ & P $2_{1} 2_{1} 2_{1}$ \\
\hline & Total reflections & 441,140 & 512,049 & $1,118,427$ & 881,784 \\
\hline & Unique reflections & $65289(5379)$ & $146002(12145)$ & $164,412(13534)$ & $133,224(10957)$ \\
\hline & Redundancy & $6.8(7.0)$ & $6.7(6.4)$ & $6.8(6.9)$ & $6.6(6.5)$ \\
\hline & Completeness (\%) & $100(100)$ & $100(100)$ & $100(100)$ & $100(100)$ \\
\hline & Mean I/sigma (I) & $14.4(2.25)$ & $15.06(2.3)$ & $20.61(2.25)$ & $19.50(2.31)$ \\
\hline & RMSD bond angle $\left({ }^{\circ}\right)$ & 1.26 & 1.25 & 1.51 & 1.57 \\
\hline & Ramachandran plot statistics & & & & \\
\hline & Favored regions (\%) & 97 & 98 & 97 & 97.6 \\
\hline & Additional allowed regions (\%) & 2.68 & 1.86 & 2.82 & 2.1 \\
\hline & Disallowed regions (\%) & 0.32 & 0.14 & 0.18 & 0.3 \\
\hline
\end{tabular}

Table 2. Anti-proliferative activities of the test compounds against three cancer cell lines. ${ }^{a} \mathrm{IC}_{50}=$ compound concentration required to inhibit tumor cell proliferation by $50 \%$. Data are expressed as the mean $\pm \mathrm{SD}$ from the dose-response curves of at least three independent experiments

\begin{tabular}{lcc}
\hline Cell lines & \multicolumn{2}{c}{$\mathrm{IC}_{50}{ }^{a}(\mathrm{nM})$} \\
& MPC-6827 & SKLB060 \\
\hline A2780 & $3.162 \pm 0.034$ & $1.369 \pm 0.476$ \\
SKVO3 & $4.301 \pm 0.099$ & $2.681 \pm 0.034$ \\
H460 & $4.633 \pm 0.198$ & $2.508 \pm 0.017$ \\
A549 & $3.227 \pm 0.376$ & $4.392 \pm 0.762$ \\
HepG2 & $4.213 \pm 0.443$ & $3.236 \pm 0.872$ \\
HCT-116 & $6.631 \pm 0.761$ & $6.781 \pm 1.873$ \\
HCC827 & $5.873 \pm 6.214$ & $6.352 \pm 0.442$ \\
MDA-MB-231 & $4.342 \pm 0.376$ & $1.971 \pm 0.092$ \\
\hline
\end{tabular}

Table 3. Drug tolerances to selected compounds among different drug-resistant cancer cells. ${ }^{a} \mathrm{IC}_{50}=$ compound concentration required to inhibit tumor cell proliferation by $50 \%$. Data are expressed as the mean $\pm \mathrm{SD}$ from the dose response curves of at least three independent experiments. ${ }^{b}$ Drug resistance index: $\left(\mathrm{IC}_{50}\right.$ of drug-resistant cancer cells $) /\left(\mathrm{IC}_{50}\right.$ of parental cancer cell). ${ }^{c} \mathrm{ND}$, not detected

\begin{tabular}{lcccc}
\hline & \multicolumn{4}{c}{$\mathrm{IC}_{50^{a}}$ mean $\pm \mathrm{SE}(\mathrm{nM})$} \\
\hline Cell lines & Paclitaxel & Vinblastine & Adriamycin & SKLB60 \\
A2780 & $58.09 \pm 24.10$ & $\mathrm{ND}^{c}$ & $\mathrm{ND}$ & $1.981 \pm 0.060$ \\
A2780/T & $56600 \pm 56198$ & $\mathrm{ND}$ & $\mathrm{ND}$ & $6.225 \pm 0.708$ \\
DRI ${ }^{b}$ & 964.0 & $\mathrm{ND}$ & $\mathrm{ND}$ & 3.1 \\
HCT-8 & $\mathrm{ND}$ & $14.77 \pm 3.151$ & $\mathrm{ND}$ & $2.765 \pm 0.823$ \\
HCT-8/V & $\mathrm{ND}$ & $5205 \pm 13$ & $\mathrm{ND}$ & $30.59 \pm 28.94$ \\
DRI & $\mathrm{ND}$ & 352.4 & $\mathrm{ND}$ & 11.1 \\
MCF-7 & $\mathrm{ND}$ & $\mathrm{ND}$ & $32.27 \pm 19.46$ & $4.910 \pm 0.018$ \\
MCF-7/ADR & $\mathrm{ND}$ & $\mathrm{ND}$ & $9153 \pm 56.19$ & $7.782 \pm 0.736$ \\
DRI & $\mathrm{ND}$ & $\mathrm{ND}$ & 283.6 & 1.6 \\
\hline
\end{tabular}

\section{Statistical analysis}

The data from multiple experiments were expressed as means \pm SD. Student's t-test was employed for data analysis. Statistical significance was set at $\mathrm{P}<0.05$.

\section{Results}

In vitro antiproliferative activities

SKLB060 and MPC-6827 were evaluated for their anti-proliferative activities against eight cancer cell lines by MTT assay (Table 2). SKLB060 showed strong activity in these cancer cells with $\mathrm{IC}_{50}$ values in the range 1.37-6.78 $\mathrm{nM}$. The effect was comparable width that of MPC-6827. Drug resistance has become a serious problem for first-line chemotherapy. The common mechanisms of resistance identified in preclinical or clinical studies include the overexpression of a cellular membrane protein called P-glycoprotein (P-gp) or changes in the levels of expression of different $\beta$-tubulin isotypes ( $\beta$-III gene) $[15,20]$. For example, 
Yan et al.: SKLB060 Reversibly Binds to Colchicine Site of Tubulin with Efficious Antitumor
Activity

Table 4. Summary of tumor growth inhibition. ${ }^{a} \mathrm{Q} 2 \mathrm{D}$, every 2 days; Q7D, every 7 days. ${ }^{b} \mathrm{NA}$, not applicable. ${ }^{\mathrm{c}} \mathrm{P}$ $<0.001$

\begin{tabular}{|c|c|c|c|c|c|c|c|c|c|c|c|c|}
\hline \multirow{2}{*}{$\begin{array}{l}\text { Tumor } \\
\text { Model }\end{array}$} & \multirow[b]{2}{*}{ Compounds } & \multirow{3}{*}{$\begin{array}{c}\text { Dose } \\
(\mathrm{mg} / \mathrm{kg})\end{array}$} & \multicolumn{2}{|l|}{ Administration } & \multirow[b]{2}{*}{ Death/All } & \multicolumn{2}{|c|}{ Body weight (g) } & \multicolumn{3}{|c|}{ Tumor volume $\left(\mathrm{mm}^{3}\right)$} & \multicolumn{2}{|c|}{ Tumor weight (g) } \\
\hline & & & Schedule ${ }^{a}$ & Route & & Begin & End & Begin & End & $T / C(\%)$ & $\mathrm{x} \pm \mathrm{SD}$ & $\begin{array}{c}\text { Inhibition } \\
(\%)\end{array}$ \\
\hline \multirow{5}{*}{ A2780 } & Control & & $Q 2 \mathrm{D} \times 10$ & IV & $0 / 6$ & $20.7 \pm 0.7$ & $23.6 \pm 0.6$ & 148.0 & 1512.5 & $\mathrm{NA}^{b}$ & $1.64 \pm 0.25$ & NA \\
\hline & SKLB060 & 2.5 & $\mathrm{Q} 2 \mathrm{D} \times 10$ & IV & $0 / 6$ & $21.0 \pm 1.0$ & $21.8 \pm 0.5$ & 137.0 & 260.7 & 18.6 & $0.25 \pm 0.10^{c}$ & 85.0 \\
\hline & SKLB060 & 10 & $\mathrm{Q} 2 \mathrm{D} \times 10$ & IV & $0 / 6$ & $20.8 \pm 0.7$ & $21.8 \pm 0.4$ & 138.3 & 153.7 & 10.9 & $0.21 \pm 0.03 \mathrm{c}$ & 87.5 \\
\hline & PTX & 30 & $Q 7 D \times 3$ & IP & $0 / 6$ & $21.0 \pm 0.7$ & $18.2 \pm 0.4$ & 138.1 & 184.8 & 13.1 & $0.28 \pm 0.07 \mathrm{c}$ & 82.9 \\
\hline & MPC-6827 & 2.5 & $Q 7 D \times 3$ & IV & $0 / 6$ & $20.5 \pm 1.5$ & $17.8 \pm 0.3$ & 139.8 & 153.8 & 10.8 & $0.16 \pm 0.05 \mathrm{c}$ & 90.24 \\
\hline \multirow{5}{*}{ A2780/T } & Control & - & $\mathrm{Q} 2 \mathrm{D} \times 10$ & IV & $0 / 6$ & $20.3 \pm 0.7$ & $21.5 \pm 0.5$ & 155.1 & 1237.4 & NA & $1.27 \pm 0.68$ & NA \\
\hline & SKLB060 & 2.5 & $\mathrm{Q} 2 \mathrm{D} \times 10$ & IV & $0 / 6$ & $20.3 \pm 1.1$ & $22.2 \pm 0.9$ & 153.2 & 371.0 & 30.4 & $0.36 \pm 0.20^{c}$ & 72.1 \\
\hline & SKLB060 & 5 & $\mathrm{Q} 2 \mathrm{D} \times 10$ & IV & $0 / 6$ & $20.7 \pm 0.9$ & $21.2 \pm 0.6$ & 161.9 & 274.3 & 21.2 & $0.21 \pm 0.06^{c}$ & 83.9 \\
\hline & SKLB060 & 10 & $\mathrm{Q} 2 \mathrm{D} \times 10$ & IV & $0 / 6$ & $20.0 \pm 0.6$ & $20.4 \pm 0.4$ & 149.6 & 243.6 & 20.4 & $0.17 \pm 0.08^{c}$ & 86.9 \\
\hline & PTX & 30 & $Q 7 D \times 3$ & IP & $0 / 6$ & $20.3 \pm 0.8$ & $19.4 \pm 1.0$ & 155.6 & 936.4 & 75.4 & $0.79 \pm 0.41$ & 37.7 \\
\hline \multirow{4}{*}{ MCF-7 } & Control & -- & $\mathrm{Q} 2 \mathrm{D} \times 10$ & IV & $0 / 6$ & $21.0 \pm 0.5$ & $23.1 \pm 0.4$ & 144.4 & 1837.2 & NA & $2.13 \pm 0.80$ & NA \\
\hline & SKLB060 & 5 & $\mathrm{Q} 2 \mathrm{D} \times 10$ & IV & $0 / 6$ & $20.3 \pm 0.9$ & $21.0 \pm 1.1$ & 138.8 & 182.2 & 10.3 & $0.22 \pm 0.09 \mathrm{c}$ & 89.9 \\
\hline & SKLB060 & 10 & $Q 2 D \times 10$ & IV & $0 / 6$ & $20.1 \pm 0.7$ & $20.0 \pm 0.9$ & 145.3 & 122.0 & 6.6 & $0.09 \pm 0.04$ & 95.9 \\
\hline & ADM & 4 & $Q 7 D \times 3$ & IP & $0 / 6$ & $20.1 \pm 0.6$ & $18.4 \pm 1.6$ & 145.9 & 395.6 & 21.3 & $0.38 \pm 0.20^{\circ}$ & 82.2 \\
\hline \multirow{5}{*}{$\begin{array}{l}\text { MCF-7 } \\
\text { /ADR }\end{array}$} & Control & -- & $\mathrm{Q} 2 \mathrm{D} \times 10$ & IV & $0 / 6$ & $20.7 \pm 1.1$ & $22.7 \pm 2.0$ & 170.4 & 1206.2 & NA & $1.36 \pm 0.53$ & NA \\
\hline & SKLB060 & 2.5 & $\mathrm{Q} 2 \mathrm{D} \times 10$ & IV & $0 / 6$ & $20.4 \pm 0.9$ & $20.9 \pm 1.0$ & 163.7 & 338.4 & 29.2 & $0.29 \pm 0.09 \mathrm{c}$ & 78.4 \\
\hline & SKLB060 & 5 & $\mathrm{Q} 2 \mathrm{D} \times 10$ & IV & $0 / 6$ & $20.7 \pm 1.0$ & $20.6 \pm 1.0$ & 163.9 & 238.7 & 20.6 & $0.27 \pm 0.10^{\circ}$ & 80.2 \\
\hline & SKLB060 & 10 & $Q 2 \mathrm{D} \times 10$ & IV & $0 / 6$ & $20.5 \pm 1.1$ & $20.5 \pm 0.9$ & 163.5 & 174.5 & 15.1 & $0.17 \pm 0.06^{c}$ & 87.6 \\
\hline & ADM & 4 & $Q 7 D \times 3$ & IP & $0 / 6$ & $20.4 \pm 1.6$ & $19.6 \pm 1.0$ & 161.5 & 959.8 & 83.9 & $0.91 \pm 0.28$ & 33.3 \\
\hline
\end{tabular}

ADM-resistant human breast carcinoma cell line MCF-7/ADR, vinblastine-resistant human colon cancer cell line HCT-8/V, and PTX-resistant human ovarian cancer cell lines A2780/T overexpress P-gp [21-23]. Hence, we analyzed the activity of SKLB060 in these resistant and related sensitive cancer cells. As shown in Table 3, SKLB060 exhibited potent cytotoxic activities in both sensitive and resistant cells, and the $\mathrm{IC}_{50}$ values of SKLB060 in A2780/T, HCT-8/V, and MCF-7/ADR cell lines were 6.225, 30.59, and 7.782 nM, respectively. SKLB060 had much lower drug resistance indexes (3.1 for A2780/T, 11.1 for HCT-8/V, and 1.6 for MCF-7/ADR) than PTX (964.0 for A2780/T), cisplatin (352.4 for HCT-8/V), and ADM (283.6 for MCF-7/ADR). These results suggested that SKLB060 might be useful in the treatment of drug refractory tumors, especially those resistant to other anti-tubulin drugs.

Antitumor activity in vivo in four xenograft models

To investigate whether SKLB060 has antitumor effects in both sensitive and resistance tumor models, we established four xenograft models using two ovarian cancer A2780 cell lines (A2780, A2780/T) and two human breast cancer cell lines (MCF-7 and MCF-7/ADR). The administration, dosing schedules, and results are presented in Table 4. As displayed in Fig. 1, SKLB060 showed a remarkable ability to reduce tumor growth in all four xenograft tumor models. In the A2780 xenograft model, treatment with $2.5 \mathrm{mg} / \mathrm{kg}$ and $10 \mathrm{mg} / \mathrm{kg}$ (intravenous (i.v.) administration, once every 2 days, 10 times total Q2D×10) SKLB060 significantly suppressed tumor growth (Fig. 1A), and the inhibition rates were $85.0 \%$ and $87.5 \%$, respectively. In addition, the MPC-6827 group (i.v. administration, $2.5 \mathrm{mg} / \mathrm{kg}$, once every 7 days, 3 times total) showed $90.24 \%$ inhibition and the PTX treated group (intraperitoneal (i.p.) administration, $30 \mathrm{mg} / \mathrm{kg}$, once every 7 days, 3 times total) showed $82.9 \%$ inhibition. In the A2780/T xenograft nude mice model, treatment with SKLB060 led to dose-dependent and significant inhibition of tumor growth; 2.5, 5, and $10 \mathrm{mg} / \mathrm{kg}$ (i.v. administration, once every 2 days, 10 times total) of SKLB060 inhibited tumor growth by $72.1 \%, 83.9 \%$, and $86.9 \%$, respectively. In contrast, the PTX treated group (i.p. administration, $30 \mathrm{mg} / \mathrm{kg}$, once every 7 days, 3 times total) showed only $37.7 \%$ inhibition (Fig. 1B). Compared with the control vehicle-treated mice, SKLB060 did not cause obvious body weight loss, but significant weight loss was observed in the PTX and MPC-6827 groups (Fig. 1A, 1B and Table 4). No gross body weight loss or pathological effects in hepatic, pleural, renal, splenic, or cardiac organ systems were observed in the SKLB060-treated A2780 model (Fig. 2). Similar results were obtained in the MCF-7 and MCF-7/ADR models. In the MCF-7 xenograft model, treatment with 
Fig. 1. In vivo anti-cancer activity of SKLB060. (A-D) A2780, A2780/T, MCF-7 and MCF-7/ADR cells $\left(5 \times 10^{6}\right)$ were subcutaneously implanted into groups of mice. Treatments were commenced when the average tumor volume reached about $100 \mathrm{~mm}^{3}$. Thereafter, tumor volumes and body weights were recorded every 2 days. (A) Mice bearing A2780 cancer cells were injected with MPC6827 (i.v. administration, $2.5 \mathrm{mg}$ / $\mathrm{kg}$, once every 7 days, 3 times total) or PTX (i.p. administration, $30 \mathrm{mg} /$ $\mathrm{kg}$, once every 7 days, 3 times total) or SKLB060 (i.v. administration, 2.5 or $10 \mathrm{mg} / \mathrm{kg}$, once every 2 days, 10 times total), or were treated with vehicle $(2.5 \%$ Tween-80 and $2.5 \%$ ethanol). Tumor volumes, body weights, and tumor weights of A2780 model group were recorded. (B) Mice bearing A2780/T cancer cells were injected with PTX (i.p. administration, $30 \mathrm{mg} / \mathrm{kg}$,

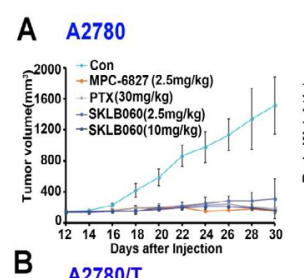

B A2780/T

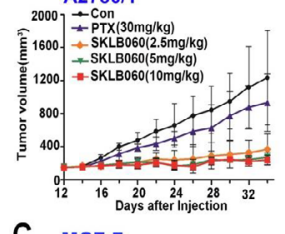

C MCF-7

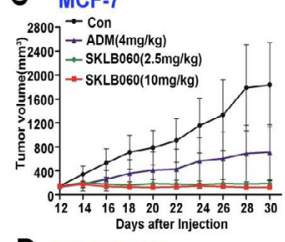

\section{MCF-7IADR}

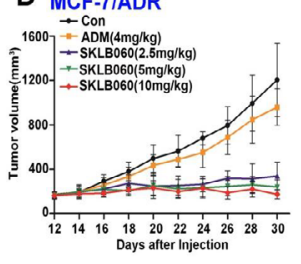

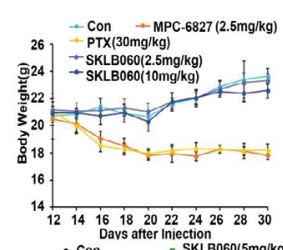
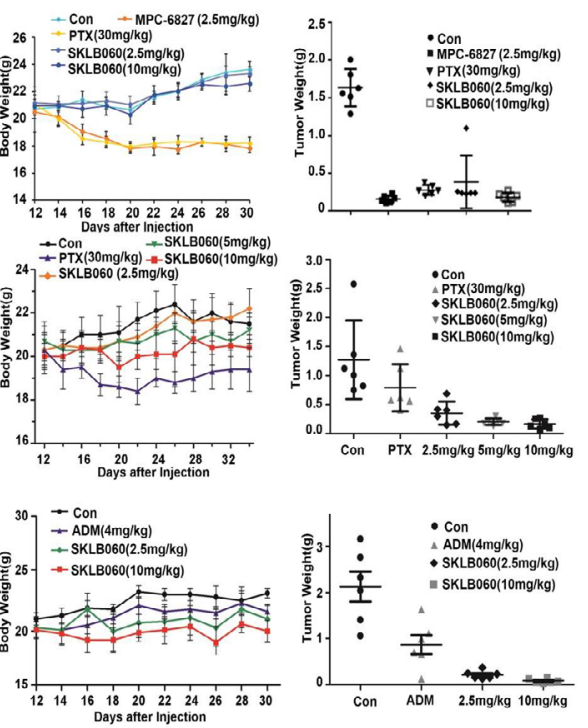

- Con
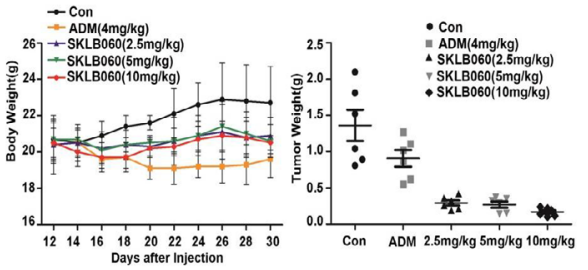

once every 7 days, 3 times total) or

SKLB060 (i.v. administration, 2.5, 5, or $10 \mathrm{mg} / \mathrm{kg}$, once every 2 days, 10 times total), or were treated with vehicle. Tumor volumes, body weights, and tumor weights were recorded. (C) Mice bearing MCF-7 cancer cells were injected with ADM (i.p. administration, $4 \mathrm{mg} / \mathrm{kg}$, once every 7 days, 3 times total) or SKLB060 (i.v. administration, 2.5 or $10 \mathrm{mg} / \mathrm{kg}$, once every 2 days, 10 times total), or were treated with vehicle. Tumor volumes, body weights, and tumor weights were recorded. (D) Mice bearing MCF-7/ADR cancer cells were injected with ADM (i.p. administration, $4 \mathrm{mg} / \mathrm{kg}$, once every 7 days, 3 times total) or SKLB060 (i.v. administration, $2.5,5$, or $10 \mathrm{mg} / \mathrm{kg}$, once every 2 days, 10 times total), or were treated with vehicle. Tumor volumes, body weights, and tumor weights were recorded. Con: control.

5 and $10 \mathrm{mg} / \mathrm{kg}$ (i.v. administration, once every 2 days, 10 times total) of SKLB060 significantly suppressed tumor growth (Fig. $1 \mathrm{C})$, and the inhibition rates were $89.9 \%$ and $95.9 \%$, respectively, compared with $82.2 \%$ inhibitory effects in the ADM-treated group (i.p. administration, $4 \mathrm{mg} / \mathrm{kg}$, once every 7 days, 3 times total). In the MCF-7/ADR xenograft nude mice model, treatment with $2.5,5$, and $10 \mathrm{mg} / \mathrm{kg}$ SKLB060 (i.v. administration, once every 2 days, 10 times total) showed inhibition rates of $78.4 \%, 80.2 \%$, and $87.6 \%$, respectively (Fig. 1D). Compared with the control vehicle-treated

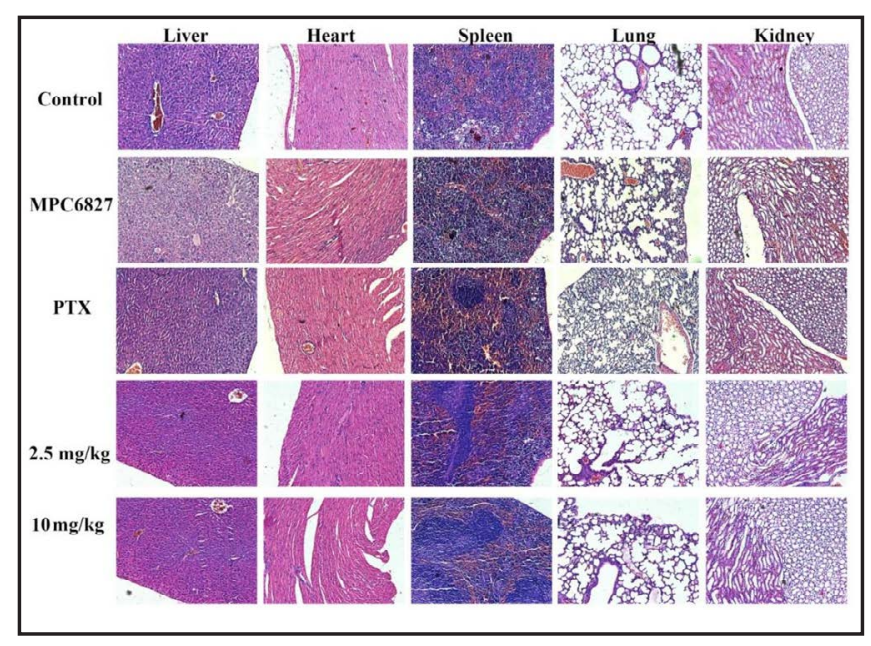

Fig. 2. Histopathological changes of A2780 xenograft models treated with SKLB060, PTX, and PMC6827. 


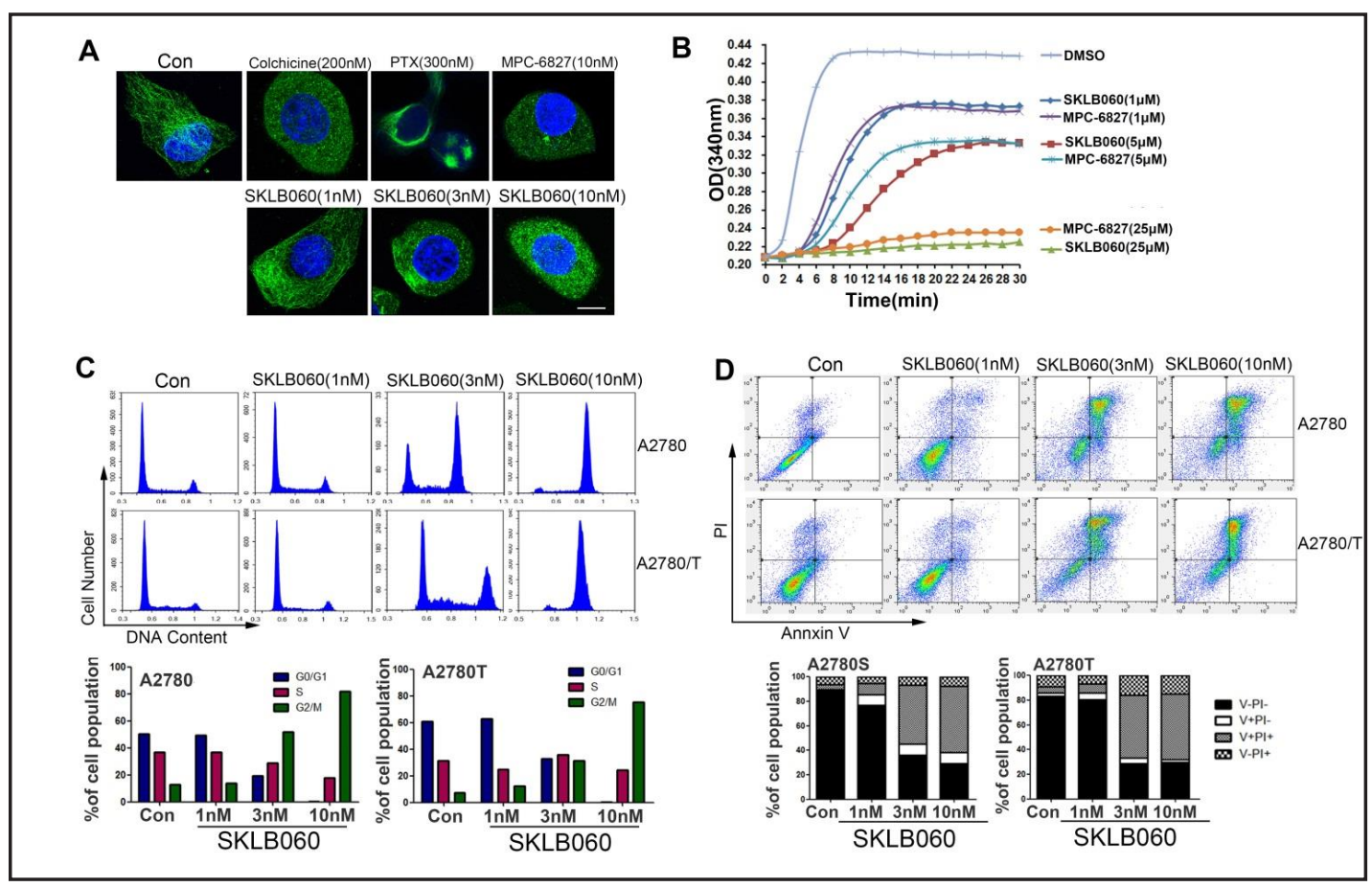

Fig. 3. Effects of compounds on the organization of cellular microtubule network and microtubule dynamics. (A) Effects of colchicine, PTX, and SKLB060 on the organization of cellular microtubule networks. A2780 cells were untreated (control) and treated with SKLB060 (1, 3, and $10 \mathrm{nM})$, PTX (300 nM), colchicine (200 $\mathrm{nM})$, or MPC-6827 (10 nM) for $16 \mathrm{~h}$. Microtubules and unassembled tubulin are shown in green and the nuclei in blue. Bar, $5 \mu \mathrm{m}$. (B) Effect of SKLB060, MPC-6827 on tubulin polymerization. Tubulin was preincubated for 5 min with SKLB060 or MPC-6827 at 1, 5, and $25 \mu \mathrm{M}$ or vehicle DMSO at room temperature before GTP was added to start the tubulin polymerization reaction. Reactions were monitored at OD340 nm at $37^{\circ} \mathrm{C}$. (C) SKLB060 caused G2/M phase arrest. A2780 and A2780T cells were treated with SKLB060 at 1, 3 , and $10 \mathrm{nM}$ for $16 \mathrm{~h}$; the control group represents the vehicle control. (D) Representative flow cytometric histograms of apoptotic A2780 and A2780T cells after a 48-h treatment with SKLB060. The cells were harvested and labeled with Annexin V-FITC and PI and analyzed by flow cytometry. Con: control.

mice, SKLB060 did not induce obvious body weight loss whereas significant weight loss was observed among the ADM groups (Fig. 1C, 1D and Table 4). These results proved that SKLB060 was effective in both drug-sensitive and drug-resistant cell lines and had a lower level of toxicity than MPC-6827.

\section{SKLB060 has a wider safety margin than MPC-6827}

To establish the safety and tolerability of SKLB060 and MPC-6827 in mice, we conducted toxicity studies to determine the no-observedadverse effect level (NOAEL: dose at which animals showed minimal weight loss and no bone marrow toxicity) and minimum effective dose (MED: minimum dose resulting in statistically significant antitumor activity relative to the vehicle control) values. As shown in Table 5, a comparison of the compound dose at MEDs to NOAELs yielded a safety margin of 6.0 for SKLB060. The safety margin for MPC6827
Table 5. SKLB060 has a wide therapeutic window compared with MPC-6827 in mice. ${ }^{a}$ Minimum dose resulting in statistically significant antitumor activity relative to vehicle control. ${ }^{b}$ No observable adverse effect level (NOAEL): Maximum dose at which no adverse clinical signs, no body weight loss, and no effects on blood cell counts, biochemistry, and bone marrow were observed. 'Safety margin defined as the ratio of NOAEL to MED

\begin{tabular}{lccc}
\hline Compound & MED $^{\text {a }}$ & NOAEL $^{\mathrm{b}}$ & Safety Marginc $^{\mathrm{c}}$ \\
\hline SKLB060 & $2.5 \mathrm{mg} / \mathrm{kg}$ & $15 \mathrm{mg} / \mathrm{kg}$ & 6 \\
MPC-6827 & $2.5 \mathrm{mg} / \mathrm{kg}$ & $2 \mathrm{mg} / \mathrm{kg}$ & 0.8 \\
\hline
\end{tabular}




\section{Cellular Physiology Cell Physiol Biochem 2018;47:489-504 \\ \begin{tabular}{c|c} 
DOI: 101159/000489983 & O 2018 The Author(s). Published by S. Karger AG, Basel \\
wwww.karger.com/cpb
\end{tabular} \\ Yan et al.: SKLB060 Reversibly Binds to Colchicine Site of Tubulin with Efficious Antitumor \\ Activity}

was 0.8 in the same model. We concluded that SKLB060 has a much wider safety margin than MPC-6827.

\section{SKLB060 inhibits tubulin polymerization}

Given that the biological activity of MPC- 6827 is reported to be mediated by it binding to tubulin, we examined the effect on the cellular microtubule network treated with SKLB060 for $24 \mathrm{~h}$ and stained for DNA (blue) and $\alpha$-tubulin (green) to investigate whether the antiproliferative activity of SKLB060 was derived from an interaction with tubulin. As shown in Fig. 3A, the microtubule network of A2780 cells exhibited a normal arrangement and organization in the absence of drug treatment. After colchicine or MPC-6827 treatment, tubulin polymerization was clearly inhibited. In contrast, treatment with PTX resulted in excessive tubulin polymerization. SKLB060 at 1, 3, and $10 \mathrm{nM}$ caused the same tubulin polymerization as that mediated by MPC-6827 in a dose-dependent manner. Furthermore, for the in vitro tubulin polymerization assay, the SKLB060 and MPC-6827 concentrations employed were 1, 5, and $25 \mu \mathrm{M}$ for each As displayed in Fig. 3B, both SKLB060 and MPC-6827 inhibited tubulin polymerization in a concentration-dependent manner. These data indicated that the mechanism of SKLB060 activity was consistent with that previously reported for MPC-6827. Our results demonstrated that SKLB060 is a novel tubulin polymerization inhibitor agent.

\section{SKLB060 induces cell cycle arrest and apoptosis on cancer cells}

To explore whether the cytotoxicity of SKLB060 is due to cell cycle arrest, we examined the effect on cell cycle progression using PI staining by flow cytometry analysis in A2780 and A2780/T cells. As shown in Fig. 3C, SKLB060 caused significant G2/M arrest in a concentration-dependent manner in both A2780 and A2780/T cells. Moreover, we tested whether SKLB060 induced apoptosis in A2780 and A2780/T cells by PI and Annexin V staining assay. SKLB060 clearly induced apoptosis in both A2780 and A2780/T cells in a concentration-dependent manner (Fig. 3D).

\section{SKLB060 binds to colchicine binding site on $\beta$-tubulin}

To confirm whether SKLB060 binds to the colchicine binding site, we carried out an EBI competition assay in A2780 cells. EBI binds to the colchicine site of $\beta$-tubulin and forms a cross-link between the Cys239 and the Cys354 residues [24]. The EBI- $\beta$-tubulin adduct can be easily separated from normal $\beta$-tubulin by western blot using $\beta$-tubulin antibody because the EBI- $\beta$-tubulin adduct band migrates faster than the normal $\beta$-tubulin band. Tubulin inhibitors binding to the colchicine-binding site can inhibit the formation of the EBI- $\beta$ tubulin adduct, which makes the assay an easy approach to identify whether inhibitors bind to colchicine-binding site [24]. As shown in Fig. 4, EBI treatment resulted in the appearance of an EBI- $\beta$-tubulin band below the normal $\beta$-tubulin band. Colchicine but not vinblastine can inhibit the formation of EBI- $\beta$-tubulin adducts. SKLB060 and MPC-6827 at 0.04, 0.2, 1, and $5 \mu \mathrm{M}$ inhibited the formation of EBI- $\beta$-tubulin adducts in a concentration-dependent manner. These results proved that both SKLB060 and MPC-6827 bind to the colchicine binding site of $\beta$-tubulin.

Fig. 4. EBI assay. Competition assay between SKLB060 $(0.04,0.2$, 1 , and $5 \mu \mathrm{M})$, MPC-6827 $(0.04,0.2$, 1 , and $5 \mu \mathrm{M}$ ), vincristine (5 and 25 $\mu \mathrm{M})$ and colchicine $(5 \mu \mathrm{M})$ with EBI $(100 \mu \mathrm{M})$ on A2780 cells. EBI

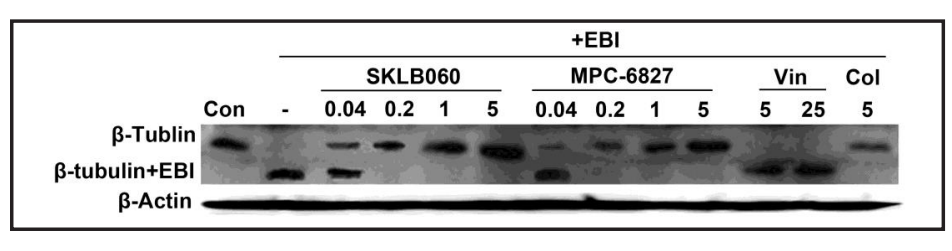
formed a $\beta$-tubulin adduct, which can be detected via western blot because it migrates faster. Compounds that preoccupy the colchicine-binding site in tubulin can inhibit the formation of the $\beta$-tubulin adduct. 


\section{Cellular Physiology and Biochemistry

Fig. 5. Effects on the HUVEC migration and tube formation. (A) HUVECs suspended in serum-free DMEM containing SKLB060 (1, 3 , and $10 \mathrm{nM}$ ) for $20 \mathrm{~h}$ were photographed under phase contrast microscopy (magnification, 100x). The control was treated with serum-free DMEM. (B) HUVECs $(1 \times$ $10^{4}$ cells) suspended in DMEM containing SKLB060 (1, 3, and $10 \mathrm{nM}$ ) were added to the Matrigel. The control was treated with DMEM alone. After incubation for $6 \mathrm{~h}$ at $37^{\circ} \mathrm{C}$, the capillary networks were photographed and quantified (magnification, $100 \times$ ). (C) Statistical data of cell migration assay. (D) Statistical data of tube formation assay. $* \mathrm{P}<0.05, * * \mathrm{P}<0.01, * * * \mathrm{P}<0.001$, significantly different compared with the control analyzed by t-test.

\section{In vitro evaluation of antivascular activity}

Most microtubule binding drugs possess vascular disrupting activities, which are thought to disrupt microtubule dynamics to induce changes in the endothelial cell shape [25]. We used a HUVEC culture assay to test the ability of SKLB060 to induce rapid changes to the shapes of the endothelial cells. Since the migration of endothelial cells is the key step in the generation of new blood vessels, a wound-healing migration assay was applied to assess the migration of HUVECs. The untreated cells migrated to fill the area that was initially scraped after $24 \mathrm{~h}$ (Fig. 5A); in contrast, compound SKLB060 significantly inhibited the migration of HUVECs in a concentration-dependent manner (Fig. 5C). We also evaluated the ability of compound SKLB060 in a tube formation assay. After seeding on Matrigel, HUVECs formed capillarylike tubules with multicentric junctions. After $6 \mathrm{~h}$ treatment in different concentrations (50-500 nM) of compound SKLB060, the capillary-like tubes were interrupted at different levels. At the two higher concentrations of SKLB060, most cells were spherical and aggregated in small clumps (Fig. 5B). Quantitative
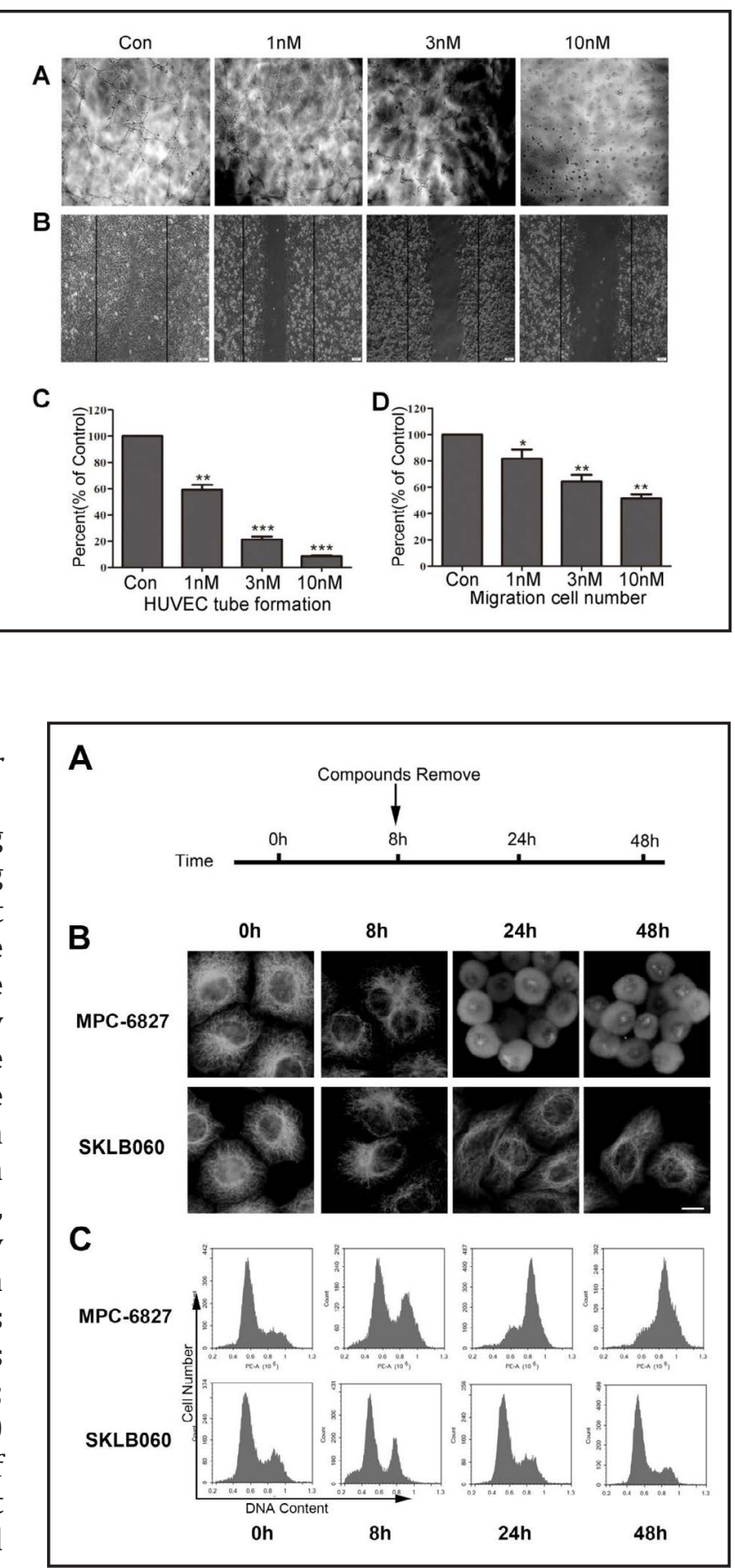

Fig. 6. SKLB060 induced reversible cellular effects. (A) Treatment of A2780 cells with SKLB060 or MPC-6827. A2780 cells were treated with $1 \mu \mathrm{M}$ SKLB060 or MPC-6827 for $8 \mathrm{~h}$, respectively, and the small molecules were washed off at $8 \mathrm{~h}$. Cells were further cultured for $48 \mathrm{~h}$. (B) Tubulin morphology was examined by immunofluorescence at 0,8 , 24 , and $48 \mathrm{~h}$, respectively. Bar, $10 \mu \mathrm{m}$. (C) Cell cycle stages were examined by flow cytometry at $0,8,24$, and $48 \mathrm{~h}$, respectively. 

Activity

image analysis showed that SKLB060 markedly decreased the capillary-like tubes in a concentration-dependent manner (Fig. 5D). To evaluate whether the inhibition of cell migration and tube formation was due to a cytotoxic action of SKLB060, we analyzed the cell proliferation of HUVECs by MTT assay to determine the $\mathrm{IC}_{50}$ value of compound SKLB060 at $48 \mathrm{~h}$. The calculated $\mathrm{IC}_{50}$ was $0.45 \pm 0.06 \mu \mathrm{M}$, which is higher than the $50 \mathrm{nM}$ required for the inhibition of cell migration and tube formation. This result indicates that the activity of SKLB060 on HUVEC migration and tube formation was not due to a cytotoxic action at the indicated concentration.

\section{SKLB060 induces reversible cellular effects}

Since the reversibility of tubulin inhibitors is an important parameter in terms of predicting in vivo efficacy and any undesirable side effects [26], we attempted to measure how SKLB060 and MPC-6827 binds to tubulin via a reported method [8]. A2780 cells were incubated for $8 \mathrm{~h}$ with $1 \mu \mathrm{M}$ SKLB060 or $1 \mu \mathrm{M}$ MPC-6827 (high enough concentrations to ensure tubulin was completely bound to the compounds), thoroughly washed, and then incubated for $24 \mathrm{~h}$ and $48 \mathrm{~h}$ (Fig. 6A). At $0 \mathrm{~h}$, the cells had typical microtubule networks (Fig. 6B). After incubation with the indicated compounds for $8 \mathrm{~h}$, the microtubules were depolymerized. After washing and another $16 \mathrm{~h}$ in culture, the depolymerization effects of MPC-6827 had progressed and almost complete loss of the microtubules was observed. With SKLB060, the microtubules began to revert to a normal appearance. After a 40-h recovery period, MPC-6827-treated cells had few microtubules, while SKLB060-treated cells showed typical microtubule networks. We also examined A2780 cells for DNA content by flow cytometry (Fig. 6C), and these data also revealed complete recovery after SKLB060 treatment, while a larger population of G2/M cells persisted after MPC-6827 treatment. These results proved that SKLB060 binds reversibly to tubulin and MPC-6827 binds irreversibly.

\section{Mitotic block reversibility of SKLB060}

Mitotic block reversibility assays were carried out following the reported method [27]. A2780 cells were treated with different concentrations of the indicated compounds at $-16 \mathrm{~h}$ time points. The compounds were completely removed at $0 \mathrm{~h}$, and incubated with no compounds for another $10 \mathrm{~h}$. Reversible ratios were calculated by dividing the minimum drug concentration required to maintain $\mathrm{CMB}$ at $10 \mathrm{~h}$ by the minimum concentration required to initially induce $\mathrm{CMB}$ at $0 \mathrm{~h}$. As shown in Fig. 7, CMBs at $0 \mathrm{~h}$ were initially induced by $100 \mathrm{nM}$ colchicine, $30 \mathrm{nM}$ colcemid, 3 nM MPC-6827, and 3 nM SKLB060. For colchicine, the same concentration (100 nM) was required to sustain CMB after $10 \mathrm{~h}$ post-washout, indicating that colchicine induced irreversible mitotic blockade (reversibility ratio: $100 \mathrm{nM} / 100 \mathrm{nM}=$

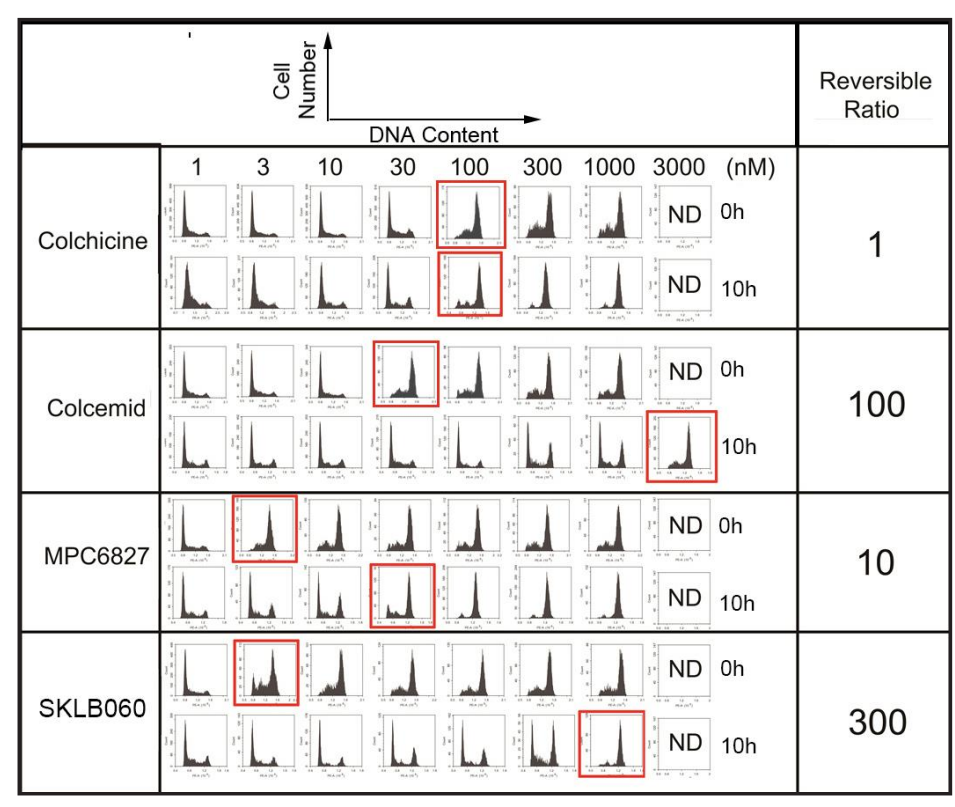

Fig. 7. Mitotic block reversibility index determination of colchicine, colcemid, MPC-6827, and SKLB060. Reversible ratios were calculated by dividing the minimum drug concentration required to maintain $\mathrm{CMB}$ at $10 \mathrm{~h}$ by the minimum concentration required to initially induce CMB at $0 \mathrm{~h}$. 

Activity

1). In contrast, a higher concentration of colcemid (3000 nM) was required for CMB at 10 $\mathrm{h}$, indicating that colcemid induced reversible mitotic blockade (reversibility ratio: 3000 $\mathrm{nM} / 30 \mathrm{nM}=100$ ). The reversibility ratios of MPC-6827 and SKLB060 were 10 and 300, indicating that MPC-6827 caused moderate reversible mitotic blockade and SKLB060 induced completely reversible mitotic blockade, which was even more reversible than colcemid. These results again proved that SKLB060 interacts reversibly with tubulin.

\section{Crystal structures of tubulin complexed with MPC-6827 or SKLB060}

$\mathrm{X}$-ray crystallography analyses were used to obtain detailed insights into the abilities of MPC-6827 and SKLB060 to tubulin and the changes to tubulin after treatment. MPC-6827, colchicine, and SKLB060 were soaked into a well-established crystallization system based on a protein complex composed of two $\alpha \beta$-tubulin heterodimers, stathmin-like protein RB3, and tubulin tyrosine ligase (T2R-TTL). Using this approach, we determined the 2.30- $\AA$ resolution apo structure of tubulin and the structures of tubulin complexed with colchicine, MPC-6827, and SKLB060 to $2.95,2.80$, and $2.20 \AA$, respectively. The overall structure of tubulin in the T2R-TTL-MPC-6827 complex could be readily superimposed on the apo-tubulin (the RMSD value for $2054 \mathrm{C} \alpha$ atoms is $0.35 \AA$ ), suggesting that the binding of MPC-6827 does not affect the global conformation of tubulin. The major conformational change concerns a movement of the $\beta$ T7 loop away from the central helix $\beta \mathrm{H} 7$ (Fig. 8B), which leads to an opening in the binding pocket for MPC-6827. Compared with the crystal structure of the tubulin-colchicine complex, MPC-6827 exhibited a similar binding mode to that of colchicine-located at the intrasubunit interface within the $\alpha \beta$ tubulin heterodimer-which was in complete contrast to a previous docking study [30]. The quinazoline ring and the methoxy benzene group of MPC-6827 superimposed on the colchicine A and C rings, respectively, while the aminomethyl linker overlapped the B ring of colchicine (Fig. 8C). Like colchicine, MPC-6827 established very few polar interactions with tubulin. The quinazoline ring and its substituent methoxyl group formed hydrophobic interactions with the side-chain alkyl groups of neighboring residues, namely, $\beta$ Ala314, $\beta$ Ala352, $\beta$ Cys239, $\beta$ Leu240, $\beta$ Leu246, $\beta$ Ala248, and $\beta$ Leu253. The methoxy benzene group of MPC-6827 formed hydrophobic contacts with the side-chain alkyl of $\beta$ Ala314, the methylthio group of $\beta$ Met257, and the aliphatic chain of $\beta$ Lys350 (Fig. 8D). Unlike colchicine, however, MPC-6827 did not form direct interactions with $\alpha$-tubulin.

Fig. 8. Comparison of the structures of the tubulin-MPC-6827 (PDB: 5XKF) and colchicine (PDB: 5XIW) complexes (A) Chemical structures of colchicine and MPC-6827, and the electron densities of MPC-6827. The Fo-Fc omit maps are contoured at $1.5 \sigma$. (B) Superimposition of tubulin and bound MPC-6827 (yellow represents the $\beta$ subunit and magenta represents the $\alpha$ subunit) and empty-tubulin (gray) (PDB: 5XP3). (C) Alignment of MPC-6827 (orange stick) and colchicine (gray stick) in the colchicine binding site. (D) Detailed interactions between MPC-6827 and the neighboring residues in the colchicine binding site. The nonbonded interactions between the receptor and ligand were created by Discovery Studio 4.5 Client.

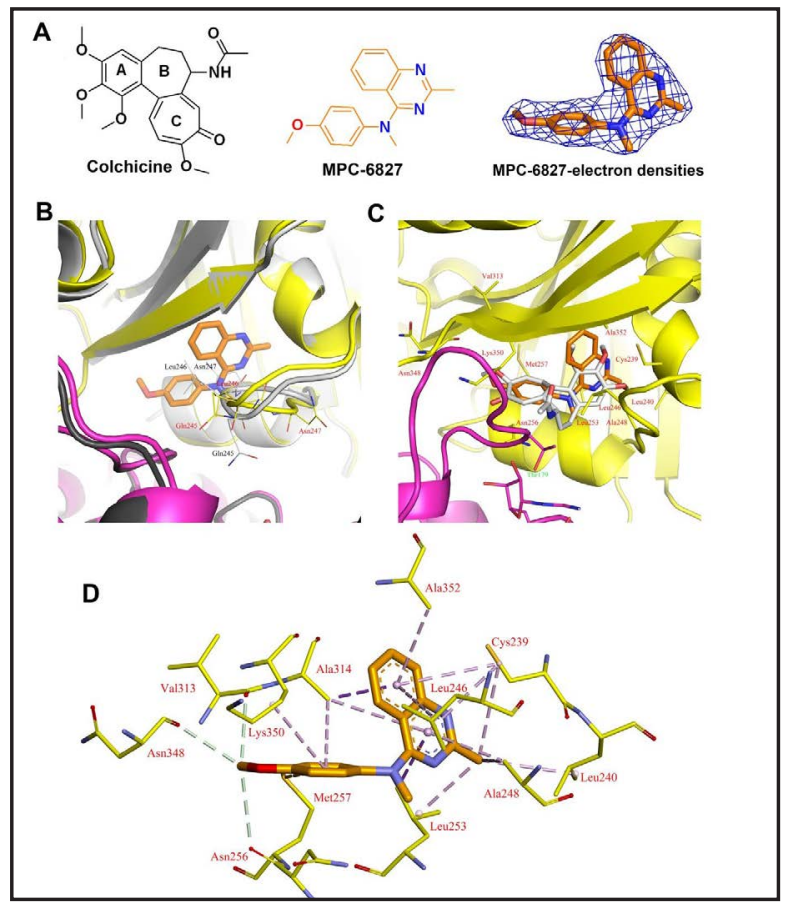




\section{Cellular Physiology

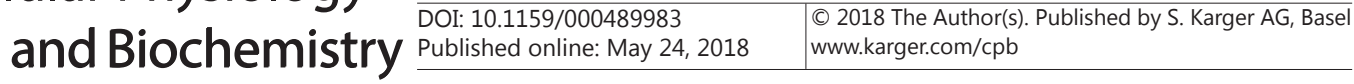 \\ Yan et al.: SKLB060 Reversibly Binds to Colchicine Site of Tubulin with Efficious Antitumor Activity}

Fig. 9. Comparison of the structures of the tubulin-MPC-6827 (PDB: 5XKF) and -SKLB060 (5XKG) complexes. (A) Chemical structures and the electron densities of SKLB060. The Fo-Fc omit maps are contoured at $1.5 \sigma$. (B) Alignment of MPC-6827 (brown-yellow stick), SKLB060 (green stick) in the colchicine binding site. (C) Hydrophobic surface of the colchicine binding site. The surfaces were colored by the hydrophobicity of the residues, from blue representing hydrophilic to brown representing hydrophobic. The hydrophobic surfaces were created by Discovery Studio 4.5 Client. (D) Detailed interactions of SKLB060 with the neighboring residues in the colchicine binding site. Red dots represent water molecules. Lavender dots represent

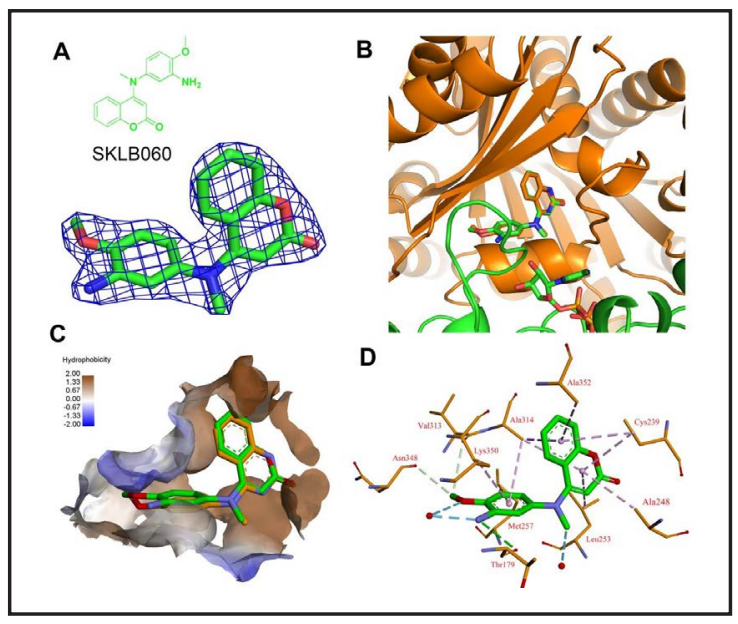
the benzene ring action center, which formed hydrophobic interactions with neighboring residues. All residues were derived from $\beta$-tubulin, except Thr179, which was from $\alpha$-tubulin. The non-bonded interactions between the receptor and ligand were created by Discovery Studio 4.5 Client.

Finally, MPC-6827 interfering with the assembly of microtubules likely shares the same mechanism as that of colchicine: the binding of MPC-6827 to the colchicine domain hinders the curve-to-straight transition of tubulin via the steric clashes between MPC-6827 and the surrounding secondary structural elements $\beta \mathrm{H} 7, \beta \mathrm{T} 7, \beta \mathrm{H} 8, \beta \mathrm{S} 8$ and $\beta S 9[11,28]$.

As shown in Fig. 9, the positions of SKLB060 entirely overlapped with the conformation of MPC-6827 in the colchicine binding site. The carbonyl of the coumarin ring in SKLB060 occupied the position of the methyl group in the quinazoline ring of MPC-6827. The coumarin ring of SKLB060 formed hydrophobic interactions with the residues of $\beta$ Ala314, $\beta A l a 352$, $\beta$ Cys239, $\beta$ Leu246, $\beta$ Ala248, and $\beta$ Leu253. The 4-methoxyphenyl group of SKLB060 formed hydrophobic interactions with $\beta$ Ala314, $\beta$ Met257, and the aliphatic chain of $\beta$ Lys350. Additionally, the aniline group of SKLB060 formed hydrogen bonds with the carboxylate oxygen of $\alpha$ Thr179 in the colchicine binding site (Fig. 9D).

The methyl group in the quinazoline ring of MPC-6827 formed hydrophobic interactions with the residues of Lue253 $\beta$, Ala248 $\beta$, Leu240 $\beta$, and Cys239 $\beta$ (Fig. 8D). When the quinazoline ring was replaced by the natural coumarin ring in the SKLB060, the carbonyl of lactone, located at the same site as the methyl group in the quinazoline ring, lost the hydrophobic contact with these residues. Due to reduction of the lipophilic group, the coumarin ring did not form the same level of hydrophobic force as that of quinazoline ring in MPC-6827 (Fig. 9C and 9D). Thus, this could provide an explanation for the differences in the reversibility of tubulin binding between MPC-6827 and SKLB060.

\section{Discussion}

Microtubules are tube-like structures formed by tubulin-dimers, which extend and assist the movement of organelles in cells [3]. An important function of microtubules is to form spindles and separate sister chromosomes into two daughter cells during cell division to help complete cell division [3, 29-31]. Microtubule inhibitors can inhibit this process by destroying the microtubules. Cancer cells can grow and eventually metastasize by continuous mitotic division [2]. Thus, mitotic inhibitors are used as cancer treatments because mitosis is inhibited more easily in cancer cells than in normal cells. Small molecules that are often used to treat cancer include mitotic inhibitors such as PTX, docetaxel, vinblastine, vincristine, and vinorelbine [1]. Current anti-tumor microtubule inhibitors tend to target PTX sites 
or vinblastine sites. However, these two tubulin-binding site inhibitors are prone to drug resistance, and have toxic side effects [3].

In our previous study, we designed a series of 4-substituted coumarins as a novel class of potent tubulin inhibitors-based on the basic skeleton structure of MPC-6827that are not substrates of MDR proteins $[17,19]$. In this study, we further report one of the 4-substituted coumarins, SKLB060, as a powerful and reversible colchicine binding site microtubule inhibitor, which is effective in multidrug-resistant tumor models. SKLB060 showed remarkable anti-cancer activities in various cancer cells lines with $\mathrm{IC}_{50}$ values in the range 1.37-6.78 nM. Furthermore, we found SKLB060 was active in multidrug-resistant cells such as A2780/T, HCT-8/V, and MCF-7/ADR. The in vivo study on four xenograft models (namely, A2780, A2780/T, MCF-7, and MCF-7/ADR) indicated that SKLB060 was effective in both drug-sensitive and drug-resistant tumors without obvious toxicity. The mechanism study confirmed that SKLB060 could inhibit tubulin polymerization in vivo and in vitro, which was confirmed by immunofluorescence and an in vitro tubulin polymerization assay, respectively, indicating that SKLB060 is a novel tubulin inhibitor. The preliminary mode of action study demonstrated that SKLB060 caused an accumulation of cells in the G2/M phase of the cell cycle and induced apoptosis in A2780 and A2780/T cells. The EBI competition assay revealed that SKLB060 binds to the colchicine site on $\beta$-tubulin. We also found that SKLB060 showed anti-vascular activity in vitro. Finally, the crystal structure of the SKLB060tubulin complex confirmed that SKLB060 binds to the colchicine site. These results proved that SKLB060 is a tubulin inhibitor that binds to the colchicine site and has anti-cancer and anti-vascular activities. Surprisingly, we found that the reversibility of SKLB060 and MPC6827 differed: MPC-6827-induced cellular effects were partially irreversible, while those of SKLB060 were totally reversible. Through a comparison and analysis of the MPC-6827tubulin and SKLB060-tubulin complexes, we found the quinazoline ring in MPC-6827 and the coumarin ring in SKLB060 adopted a similar conformation in the colchicine binding pocket. However, the coumarin ring in SKLB060, the carbonyl of lactone, which is located at the same site as the methyl group in the quinazoline ring, lost hydrophobic contact with other residues. Due to reduction of the lipophilic group, the coumarin ring did not form the same level of hydrophobic force as that of quinazoline ring in MPC-6827. Thus, this could provide an explanation for the different levels of reversibility on tubulin binding by MPC6827 and SKLB060. As the reversibility of tubulin inhibitors is important for predicting the efficacy and side effects [26], we believe that SKLB060 might be less toxic and have more potential applications.

\section{Acknowledgements}

This work was supported by grants from the National Natural Science Foundation of China (U1402222) and National Key Programs of China during the 13th Five-Year Plan Period (2018ZX09721002-001-004) and open research Fund of State Key Laboratory Breeding Base of Systematic research, development and Utilization of Chinese Medicine Resources.

All animal studies were approved by the Institutional Animal Care and Treatment Committee of Sichuan University.

\section{Disclosure Statement}

The authors declare that they have no competing interests. 
Yan et al.: SKLB060 Reversibly Binds to Colchicine Site of Tubulin with Efficious Antitumor Activity

\section{References}

1 Perez EA: Microtubule inhibitors: Differentiating tubulin-inhibiting agents based on mechanisms of action, clinical activity, and resistance. Mol Cancer Ther 2009;8:2086-2095.

2 Jordan MA, Kamath K: How do microtubule-targeted drugs work? An overview. Curr Cancer Drug Targets 2007;7:730.

3 Bhalla KN: Microtubule-targeted anticancer agents and apoptosis. Oncogene 2003;22:9075-9086.

4 Kim JS, Lee YC, Nam HT, Li G, Yun EJ, Song KS, Seo KS, Park JH, Ahn JW, Zee O: Apicularen A induces cell death through Fas ligand up-regulation and microtubule disruption by tubulin down-regulation in HM7 human colon cancer cells. Clin Cancer Res 2007;13:6509-6917.

5 Michaud LB: The epothilones: how pharmacology relates to clinical utility. Ann Pharmacother 2009;43:1294-1309. Kavallaris M: Microtubules and resistance to tubulin-binding agents. Nat Rev Cancer 2010;10:194-204. Swain SM, Arezzo JC: Neuropathy associated with microtubule inhibitors: diagnosis, incidence, and management. Clin Adv Hematol Oncol 2008;6:455-467.

8 Buey RM, Calvo E, Barasoain I, Pineda O, Edler MC, Matesanz R, Cerezo G, Vanderwal CD, Day BW, Sorensen EJ: Cyclostreptin binds covalently to microtubule pores and lumenal taxoid binding sites. Nat Chem Bio 2007;3:117-125.

-9 Field JJ, Pera B, Calvo E, Canales A, Zurwerra D, Trigili C, Rodríguez-Salarichs J, Matesanz R, Kanakkanthara A, Wakefield SJ: Zampanolide, a potent new microtubule-stabilizing agent, covalently reacts with the taxane luminal site in tubulin $\alpha, \beta$-heterodimers and microtubules. Chem Biol 2012;19:686-698.

10 Grigoryan H, Lockridge 0: Nanoimages show disruption of tubulin polymerization by chlorpyrifos oxon: implications for neurotoxicity. Toxicol Appl Pharmacol 2009;240:143-148.

11 Ravelli RBG, Gigant B, Curmi PA, Jourdain I, Lachkar S, Sobel A, Knossow M: Insight into tubulin regulation from a complex with colchicine and a stathmin-like domain. Nature 2004;428:198-202.

-12 Prota AE, Bargsten K, Northcote PT, Marsh M, Altmann KH, Miller JH, Díaz JF, Steinmetz MO: R\&uuml;cktitelbild: Structural Basis of Microtubule Stabilization by Laulimalide and Peloruside A. Angew Chem Int Edit 2014;53:1621-1625.

-13 Prota AE, Bargsten K, Diaz JF, Marsh M, Cuevas C, Liniger M, Neuhaus C, Andreu JM, Altmann KH, Steinmetz MO: A new tubulin-binding site and pharmacophore for microtubule-destabilizing anticancer drugs. P Natl Acad Sci USA 2014;111:13817-13821.

14 Yang J, Wang Y, Wang T, Jiang J, Botting CH, Liu H, Chen Q, Yang J, Naismith JH, Zhu X: Pironetin reacts covalently with cysteine-316 of $\alpha$-tubulin to destabilize microtubule. Nat Commun 2016;7:12103.

15 Lu Y, Chen J, Xiao M, Li W, Miller DD: An overview of tubulin inhibitors that interact with the colchicine binding site. Pharm Res 2012;29:2943-2971.

16 Nathan P, Zweifel M, Padhani AR, Koh DM, Ng M, Collins DJ, Harris A, Carden C, Smythe J, Fisher N: Phase I trial of combretastatin A4 phosphate (CA4P) in combination with bevacizumab in patients with advanced cancer. Clin Cancer Res 2012;18:3428-3439.

17 Kasibhatla S, Baichwal V, Cai SX, Roth B, Skvortsova I, Skvortsov S, Lukas P, English NM, Sirisoma N, Drewe J: MPC-6827: a small-molecule inhibitor of microtubule formation that is not a substrate for multidrug resistance pumps. Cancer Res. 2007;67:5865-5871.

-18 Kim LJ, Chamberlain MC, Zhu J, Raizer JJ, Grimm SA, Phuphanich S, Fadul CE, Rosenfeld S, Balch AH, Pope CC: Phase II study of verubulin (MPC-6827) for the treatment of subjects with recurrent glioblastoma naïve to treatment with bevacizumab. J Clin Oncol 2011;29:2088-2088.

-19 Cao D, Liu Y, Yan W, Wang C, Bai P, Wang T, Tang M, Wang X, Yang Z, Ma B: Design, Synthesis, and Evaluation of in vitro and in vivo Anticancer Activity of 4-Substituted Coumarins: A Novel Class of Potent Tubulin Polymerization Inhibitors. J Med Chem 2016;59:5721-5739.

20 Terry S, Ploussard G, Allory Y, Nicolaiew N, Boissièremichot F, Maillé P, Kheuang L, Coppolani E, Ali A, Bibeau F: Increased expression of class III $\beta$-tubulin in castration-resistant human prostate cancer. Br J Cancer 2011;101:951-956.

21 Budworth J, Davies R, Malkhandi J, Gant TW, Ferry DR, Gescher A: Comparison of staurosporine and four analogues: their effects on growth, rhodamine 123 retention and binding to P-glycoprotein in multidrugresistant MCF-7/Adr cells. Br J Cancer 1996;73:1063-1068. 


\section{Cellular Physiology Cell Physiol Biochem 2018;47:489-504

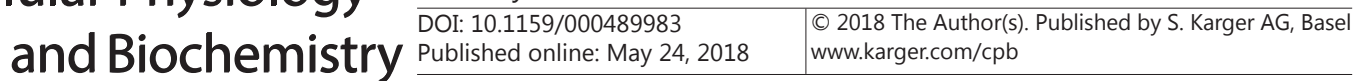 \\ Yan et al.: SKLB060 Reversibly Binds to Colchicine Site of Tubulin with Efficious Antitumor Activity}

22 Xu Y, Qiu L: Nonspecifically enhanced therapeutic effects of vincristine on multidrug-resistant cancers when coencapsulated with quinine in liposomes. Int J Nanomed 2015;10:4225-4237.

23 Zhao BX, Sun YB, Wang SQ, Duan L, Huo QL, Ren F, Li GF: Grape seed procyanidin reversal of p-glycoprotein associated multi-drug resistance via down-regulation of NF- $\mathrm{KB}$ and MAPK/ERK mediated YB-1 activity in A2780/T cells. PLoS One 2013;8:e71071.

24 Fortin S, Lacroix J, Côté MF, Moreau E, Petitclerc É, C-Gaudreault R: Quick and Simple Detection Technique to Assess the Binding of Antimicrotubule Agents to the Colchicine-Binding Site. Biol Proced Online 2010;12:113-117.

-25 Schwartz EL: Antivascular actions of microtubule-binding drugs. Clin Cancer Res 2009;15:2594-2601.

-26 Thomas NE, Thamkachy R, Sivakumar KC, Sreedevi KJ, Louis XL, Thomas SA, Kumar R, Rajasekharan KN, Cassimeris L, Sengupta S: Reversible action of diaminothiazoles in cancer cells is implicated by the induction of a fast conformational change of tubulin and suppression of microtubule dynamics. Mol Cancer Ther 2014;13:179-189.

27 Towle MJ, Salvato KA, Wels BF, Aalfs KK, Zheng W, Seletsky BM, Zhu X, Lewis BM, Kishi Y, Yu MJ: Eribulin induces irreversible mitotic blockade: implications of cell-based pharmacodynamics for in vivo efficacy under intermittent dosing conditions. Cancer Res 2011;71:496-505.

-28 Prota AE, Danel F, Bachmann F, Bargsten K, Buey RM, Pohlmann J, Reinelt S, Lane H, Steinmetz MO: The novel microtubule-destabilizing drug BAL27862 binds to the colchicine site of tubulin with distinct effects on microtubule organization. J Mol Biol 2014;426:1848-1860.

-29 Fojo AT, Menefee M: Microtubule targeting agents: basic mechanisms of multidrug resistance (MDR). Semin Oncol 2005;32:S3.

30 Shen J, Ma H, Zhang T, Liu H, Yu L, Li G, Li H, Hu M: Magnolol Inhibits the Growth of Non-Small Cell Lung Cancer via Inhibiting Microtubule Polymerization. Cell Physiol Biochem 2017;42:1789-1801.

31 Tanaka S, Miyazaki H, Shiozaki A, Ichikawa D, Otsuji E, Marunaka Y: Cytosolic Cl- Affects the Anticancer Activity of Paclitaxel in the Gastric Cancer Cell Line, MKN28 Cell. Cell Physiol Biochem 2017;42:68-80. 